\title{
Análise epidemiológica de um surto de mastite bovina em uma propriedade leiteira no Estado do Rio Grande do Sul
}

\author{
Epidemiological analysis of an outbreak of bovine mastitis in a dairy herd \\ in the state of Rio Grande do Sul
}

Aline Gil Alves Guilloux ${ }^{1,2}$, Marisa Ribeiro de Itapema Cardoso² \& Luis Gustavo Corbellini ${ }^{2}$

\section{RESUMO}

A mastite bovina é responsável por grandes prejuízos econômicos em rebanhos leiteiros em todo o mundo devido à diminuição da produção de leite, gastos com medicação, descarte e perda na qualidade do leite. O objetivo do trabalho foi de analisar, através de métodos epidemiológicos, um surto de mastite bovina ocorrido em uma propriedade leiteira no Estado do Rio Grande do Sul. O rebanho apresentava um aumento da incidência de mastite clínica caracterizado por grumos no leite. Foi feito CMT em todos os animais em lactação e os resultados do teste registrados para cada quarto mamário em uma escala subjetiva, que variou de zero (sem alteração), traços, uma, duas ou três cruzes (de acordo com a intensidade de formação de gel). Foram coletadas amostras de leite para exame bacteriológico de todos os quartos mamários com resultados de duas e três cruzes no CMT, sendo que 33,5\% dos animais (136/405) apresentaram contagem de célula somática (CCS) acima do ponto de corte estipulado em pelo menos um quarto mamário. De 149 amostras de leite coletadas, 33\% (44/126) revelaram crescimento de Sthaphylococcus aureus ou Streptococcus agalactiae. O risco de desenvolver mastite foi maior em vacas com maior produção média de leite $(\mathrm{p}=0,00765)$ e o risco de um animal apresentar mastite contagiosa (S. aureus e S. agalactiae) foi maior com o tempo de lactação $(\mathrm{p}=0,042)$. Através da investigação epidemiológica, concluiu-se que o surto foi provavelmente causado pela introdução de animais infectados no rebanho.

Descritores: bovinos, epidemiologia, mastite, surto.

\section{ABSTRACT}

Bovine mastitis is an infectious disease that causes economic losses in dairy herds due to impaired milk production and milk quality and costs with both culling and treatment. The objective of the study was to analyze an outbreak of bovine mastitis in a large dairy herd in the state of Rio Grande do Sul. The herd with 405 lactating cows showed an increased incidence of clinical mastitis characterized primary by clots in the milk. California Mastitis Test (CMT) was performed in all milking cows and milk samples were collected from those presenting $2+$ or $3+$ based on the viscosity of the gel; $33.5 \%$ of the lactating cows presented 2 + or $3+$ in the CMT test. Staphylococcus aureus and Streptococcus agalactiae were obtained from 33\% of milk samples. The odds of a cow showing mastitis according to CMT criteria increased with the increment of average milk production $(p=0.00765)$; the risk of a cow with contagious mastitis increased with the lactating period $(\mathrm{p}=0,042)$. It could be concluded through the epidemiological analysis that the outbreak has started after the introduction of new animals into the herd.

Key words: bovine, epidemiology, mastitis, outbreak. 


\section{INTRODUÇÃO}

A mastite bovina é responsável por grandes prejuízos econômicos em rebanhos leiteiros em todo o mundo e tem, basicamente, duas formas de apresentação: clínica, com sinais de inflamação na glândula e/ou formação de grumos ou pus no leite, e subclínica, que causa perda de produção sem sinais clínicos [12-14]. A mastite provoca diminuição da produção de leite, gastos com medicação, descarte de leite e perda de qualidade $[1,6]$. A infecção também pode causar perda de produção permanente por dano no epitélio secretor da glândula mamária e conseqüente descarte do animal. Os métodos de diagnóstico mais utilizados são o teste da caneca de fundo escuro, para detecção de grumos, Califórnia Mastite Teste (CMT) e contagem de células somáticas (CCS), ambos para detecção de mastite subclínica, bem como exames microbiológicos do leite $[2,13]$.

Os agentes causadores de mastite podem ser classificados em ambientais ou contagiosos. Agentes ambientais são microorganismos normalmente encontrados no local de permanência dos animais ou na sala de ordenha e os agentes contagiosos são aqueles que sobrevivem pouco tempo fora do hospedeiro e colonizam o teto e cisterna, sendo o animal infectado a fonte de infecção. S. aureus e $S$. agalactiae são os agentes contagiosos mais comuns e os patógenos ambientais de maior importância são os coliformes (principalmente Escherichia coli e Klebsiella sp.) e Streptococcus $s p$. [12,14].

A probabilidade de surgimento de uma infecção na glândula mamária está relacionada principalmente com o grau de exposição do teto aos microrganismos patogênicos, às oportunidades desses agentes penetrarem na glândula mamária e à habilidade da bactéria se multiplicar e sobreviver ao sistema imune [2].

O objetivo do trabalho foi de analisar, através de métodos epidemiológicos, um surto de mastite bovina ocorrido em uma propriedade leiteira no Estado do Rio Grande do Sul.

\section{MATERIAIS E MÉTODOS}

Uma propriedade produtora de leite com um rebanho de 405 animais em lactação, situada no Estado do Rio Grande do Sul, apresentava um aumento no número de casos clínicos de mastite. A partir de setembro de 2002, foi registrada uma

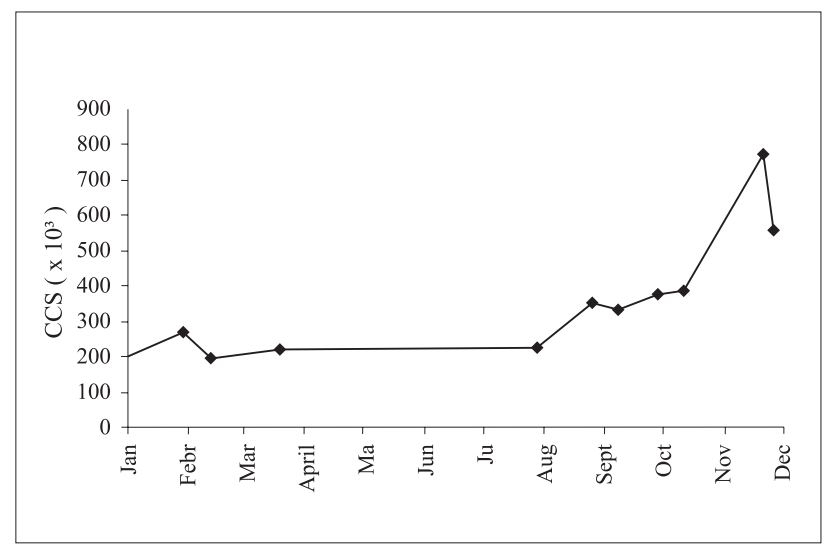

Figura 1. Contagem de células somáticas (CCS) observada no leite do tanque da propriedade no ano de 2002, anterior e durante o surto de mastite.

elevação da CCS que atingiu o pico entre outubro e novembro (Figura 1). O quadro apresentado era de intensidade leve e caracterizado basicamente pelo aparecimento de grumos no leite e leve aumento de volume no quarto afetado. Normalmente não havia uma boa resposta ao tratamento administrado, inclusive com progressão do surto. $\mathrm{O}$ antibiótico utilizado tinha como princípio ativo a neomicina e espiramicina.

Em janeiro de 2003, uma investigação epidemiológica foi desenvolvida na propriedade, ocasião em que se observou o procedimento de ordenha, coletou-se material para exames diagnósticos e informações sobre animais e manejo geral. Para obter tais informações, foi aplicado um questionário epidemiológico contendo perguntas sobre os principais fatores de risco relacionados ao desenvolvimento da mastite bovina. Os dados coletados referentes aos animais incluíram idade, dias em lactação e produção média. Também foram coletadas informações sobre mudança de procedimentos de manejo, introdução de animais, manutenção do equipamento de ordenha, origem da água e práticas terapêuticas.

Foi feito CMT em todos os animais em lactação e os resultados do teste registrados, para cada quarto mamário, em uma escala subjetiva que variou de zero (sem alteração), traços, uma, duas ou três cruzes (de acordo com a intensidade de formação de gel). Foram coletadas amostras de leite para exame bacteriológico de todos os quartos mamários com resultados de duas e três cruzes no 
CMT, o que corresponde a uma CCS de, aproximadamente, 2700 a $8100 \times 10^{3}$ células somáticas [13]. Dados clínicos tais como presença de grumos ou pus no leite foram registrados. A taxa de incidência foi calculada dividindo-se o número de casos novos, detectados durante a ordenha, pela média do número de animais ao risco, no início e no fim da ordenha [15].

As amostras de leite foram remetidas sob refrigeração para o Laboratório do Departamento de Medicina Veterinária Preventiva da Universidade Federal do Rio Grande do Sul e semeadas em ágar sangue e ágar McConkey. Foi realizado teste de sensibilidade a antimicrobianos (TSA), dos isolados em meio Muller-Hinton, frente a ampicilina, cefalotina, cloxacilina, enrofloxacina, oxacilina e associações de sulfametoxazol com trimetoprima e neomicina com espiramicina.

Os dados referentes aos animais, exame de CMT, bacteriológico e dados clínicos, foram registrados em planilhas Excel. Para análise estatística, os animais foram classificados quanto à presença de mastite (variável resposta) de duas formas, através do resultado do CMT e do exame bacteriológico. Amostras com zero, traços e uma cruz foram consideradas negativas e amostras com duas e três cruzes, positivas. Esse ponto de corte foi baseado no critério utilizado para coleta de amostras no exame bacteriológico e número médio de células somáticas, o que resulta na maior probabilidade de detectar animais infectados por bactérias não oportunistas [14]. Os resultados dos exames bacteriológicos foram agrupados em contagiosos (Staphylococcus aureus e Streptococcus agalactiae) e outros resultados, utilizando-se na análise somente os animais coletados para exame microbiológico. A associação entre presença de mastite e fatores ligados ao animal (idade, dias em lactação e produção) foi verificada através do teste de Qui-quadrado de tendência. A análise foi realizada utilizando os programas Epi Info 6.0.

\section{RESULTADOS}

Durante o exame de CMT, constatou-se que $33,5 \%$ (136/405) dos animais apresentavam resultado igual ou maior do que duas cruzes em pelo menos um quarto mamário. Foram coletadas 149 amostras de leite de 130 animais. Destes animais, $70 \%$ apresentavam mastite subclínica. Durante o teste, foram registrados três casos novos e, assim, a taxa de incidência de
Tabela 1. Resultados obtidos nos exames microbiológicos das amostras de leite coletadas dos animais com Califórnia Mastite Teste de duas e três cruzes.

\begin{tabular}{|c|c|c|}
\hline Isolamento Bacteriano & Número de casos & Freqüência (\%) \\
\hline Staphylococcus aureus ${ }^{I}$ & 18 & $14 \%$ \\
\hline Streptococcus agalactiae $^{t}$ & 17 & $13 \%$ \\
\hline Streptococcus sp. & 10 & $8 \%$ \\
\hline S. aureus e S. agalactiae ${ }^{2}$ & 9 & $9 \%$ \\
\hline Staphylococcus spp. & 5 & $4 \%$ \\
\hline Enterobactéria & 1 & $1 \%$ \\
\hline Contaminante & 12 & $10 \%$ \\
\hline Não Houve Crescimento & 54 & $43 \%$ \\
\hline Total & 126 & $100 \%$ \\
\hline
\end{tabular}

${ }^{1}$ Isolados de animais individualmente; ${ }^{2}$ Isolados do mesmo animal

mastite clínica foi calculada em 0,9 casos a cada 100 animais expostos ao risco, ou seja, em média 3,5 casos novos a cada 405 animais ordenhados.

Das amostras de leite coletadas, foram processados exames de 126 animais e 33\% (44/126) revelaram crescimento de $S$. aureus ou $S$. agalactiae. $O$ resultado bacteriológico está apresentado na tabela 1. O TSA revelou a existência de amostras de $S$. aureus resistentes ao principio ativo que estava sendo utilizado (neomicina e espiramicina). Em 7\% dos casos (9/126) foram observadas infecções mistas, com os dois agentes mais prevalentes na mesma amostra. Dentre animais em que houve o isolamento de S.aureus ou $S$. agalactiae, 84,1\% (37/44) não apresentavam sinais clínicos.

A avaliação do histórico da propriedade revelou que, em outubro de 2001, foram contratados funcionários novos para ordenha e houve a introdução de 70 animais no rebanho, comprados de uma propriedade da região. No final de novembro, ocorreu um problema no filtro da ordenhadeira mecânica que forçava a interrupção da ordenha e, em dezembro, foi constatado que o nível de vácuo era de 45 Kpa. Durante a visita foi observado que a desinfecção dos tetos ("predipping") era realizada de forma rápida (menos de 30 segundos) e antes do teste da caneca de fundo escuro. A infusão intramamária de antibiótico para tratamento dos animais afetados não era precedida por desinfecção do teto e a escolha do princípio ativo era feita de forma empírica.

De acordo com as análises realizadas, o risco de desenvolver mastite foi maior em vacas com maior produção média de leite $(\mathrm{p}=0,007$; Figura 2$)$. Não houve associação linear significativa entre idade 


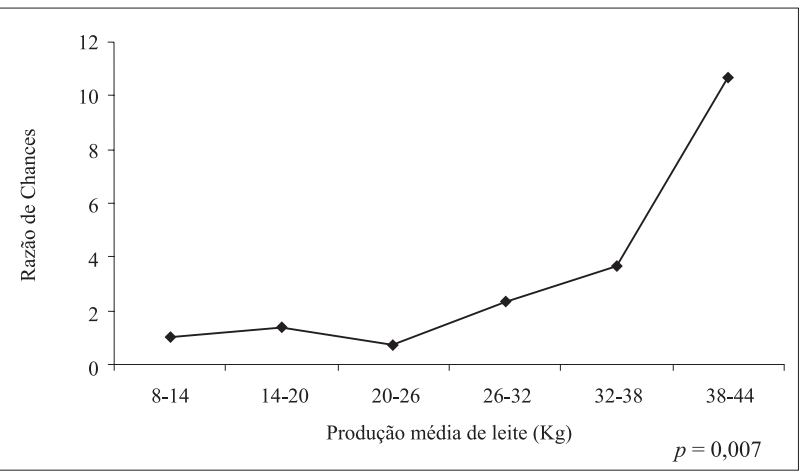

Figura 2. Razão de Chances (risco) de um animal apresentar duas ou três cruzes no Califórnia Mastite Teste (critério de classificação de mastite) de acordo com a produção média individual de leite no rebanho estudado.

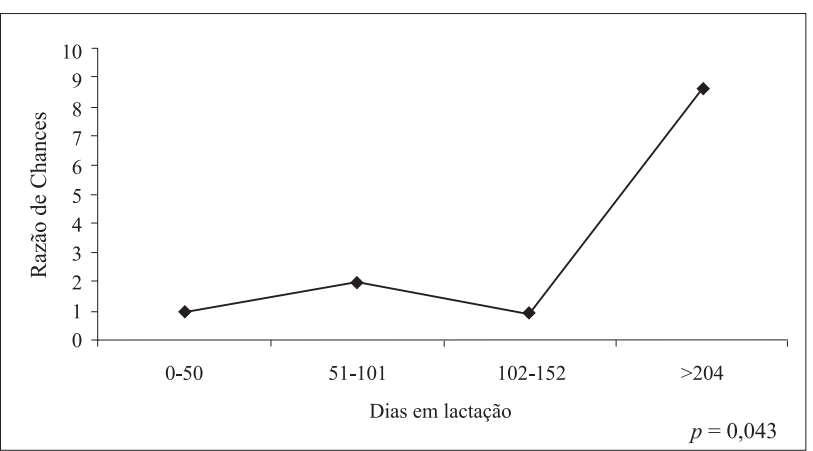

Figura 3. Razão de Chances (Risco) de um animal apresentar mastite contagiosa por Staphyloccus aureus ou Streptococcus agalactiae, relacionada com o tempo em lactação no momento do surto, nos animais que apresentavam duas e três cruzes no Califórnia Matite Teste.

e CMT positivo $(\mathrm{p}=0,242)$. Houve aumento do risco até 75 meses, seguido de uma queda após essa idade. O risco de um animal apresentar mastite contagiosa (S. aureus e S. agalactiae) foi maior com o tempo de lactação ( $\mathrm{p}=0,042$, figura 3 ).

\section{DISCUSSÃO}

Os surtos de mastite, como o ocorrido nessa propriedade, podem ser responsáveis por perdas econômicas causadas por custos de diagnóstico, tratamentos, além de descarte de leite e animais. Alguns autores descrevem perdas na produção de leite da ordem de $9 \%$ a $25 \%$ em rebanhos com mais de $500 \times 10^{3}$ células somáticas por $\mathrm{ml}$ de leite do tanque $[4,13]$. Visando estimular o produtor a investir na prevenção desse problema, está em vigor a Instrução Normativa n. ${ }^{\circ} 51$ que estabelece que a CCS do leite do tanque nas propriedades do Rio Grande do Sul deve estar abaixo de $1000 \times 10^{3}$. Entrará em vigor o limite de $750 \times 10^{3}$ em julho de 2008, baixando até o limite máximo de 400 x 10³, em 2011 [3].

Altas CCS no leite do tanque, conforme observado no surto em questão, indicam altos níveis de infecção subclínica [12,13]. Esse fato foi confirmado pelo teste CMT, onde aproximadamente um terço dos animais apresentaram CCS acima do ponto de corte estipulado (duas cruzes ou $2700 \times 10^{3}$ células somáticas por $\mathrm{ml}$ de leite em pelo menos um quarto mamário) e, dentre estes, a maioria apresentava quadro subclínico. Estudos anteriores demonstram que aproximadamente $32 \%$ dos quartos mamários de um rebanho com CCS acima de $1000 \times 10^{3}$ estão infectados, similar ao observado nesse rebanho [8].

Quartos mamários infectados por S.aureus e Streptococcus agalactiae sofrem aumento da CCS para valores entre $900 \times 10^{3}$ e $2240 \times 10^{3}$ células por $\mathrm{ml}$ de leite [9]. O resultado do exame bacteriológico revelou predomínio desses agentes, os quais são os prováveis responsáveis pelo súbito aumento da CCS observado no rebanho. Esses agentes causam aumento na CCS anterior ao aparecimento dos sintomas clínicos de mastite e essa contagem anormal persiste após a regressão do quadro, podendo resultar numa alta frequiência de animais com CCS elevada no rebanho, mesmo sem apresentação de sinais clínicos [2,5,12]. A ocorrência de infecções mistas foi comum devido ao grande potencial contagioso dos principais agentes.

Staphylococcus aureus é uma bactéria que sobrevive na superfície dos tetos e mãos de ordenhadores e geralmente causa infecções subclínicas. Os casos clínicos causados por essa bactéria usualmente são de intensidade leve e caracterizados pela formação de grumos evidentes. Sua cura no período de lactação é baixa, principalmente em casos crôni$\cos$, pois esta bactéria causa a formação de microabscessos, impedindo a ação do antibiótico [12]. A resistência ao antimicrobiano utilizado, associado ao baixo percentual de cura do $S$. aureus durante a lactação, explicam a progressão de alguns casos de mastite mesmo após o início do tratamento [13]. $S$. agalactiae é uma bactéria contagiosa que provoca grande aumento na CCS e o seu principal reservatório é o leite proveniente de quartos infectados, não tendo tanta capacidade de colonizar a pele como o S. aureus [12]. O S. agalactiae é de fácil controle, pois responde bem à terapia durante a lactação, mesmo nos casos subclínicos, e tem a incidência drasticamente reduzida através de "posdipping" e 
tratamento de vacas secas [10,12]. Apesar de haver relatos de resistência a antimicrobianos no gênero Streptococcus spp., as amostras isoladas desse surto eram suscetíveis ao antimicrobiano utilizado [10]. Muitas espécies de estafilococos coagulase negativa são freqüentemente isoladas de rebanhos leiteiros, porém, são geralmente associadas a casos subclínicos ou de intensidade leve. Alguns autores classificam essas bactérias como oportunistas [13].

A contratação de funcionários novos, não habituados à rotina da ordenha, poderia causar estresse para os animais e, principalmente, falha no procedimento da ordenha. Fontes de estresse podem aumentar a CCS, principalmente em animais com histórico de mastite [7]. A introdução de animais provenientes de uma propriedade diferente no lote em lactação, aliada a algumas práticas inadequadas de manejo, pode ter ocasionado a introdução e disseminação de agentes contagiosos [4]. Interrupções constantes na ordenha, causadas por problemas de manutenção do equipamento, prejudicam o correto esgotamento do úbere, aumentando a quantidade de leite residual e, assim, a quantidade de nutrientes disponíveis para a proliferação bacteriana [2]. O nível de vácuo que estava $4 \mathrm{Kpa}$ acima do recomendado já havia sido corrigido para valores ideais (entre 37 e $41 \mathrm{Kpa}$ ) na época da visita [11]. Porém, o excesso de vácuo ocasiona aumento da CCS por lesão mecânica e facilita a invasão bacteriana ao causar lesões na ponta dos tetos. [2,4].

A realização do "predipping", antes do teste da caneca de fundo escuro, associado ao fato de não respeitar o tempo de ação mínimo de 30 segundos [2], podem ter sido fatores implicados no surto observado por tornar ineficiente o processo de desinfecção [4]. O procedimento pré-ordenha correto inicia pela remoção de sujeiras grosseiras dos tetos. Em seguida, deve ser realizado o teste da caneca de fundo escuro e, opcionalmente, o "predipping". Os tetos devem ser completamente secos, após o período de ação do anti-séptico, com toalha de papel descartável para, então, colocar as teteiras [13,14].

A aplicação do antimicrobiano intramamário deve ser feita com o teto limpo e previamente desinfetado com álcool 70\%. A aplicação do antimicrobiano sem medidas higiênicas pode introduzir mecanicamente agentes presentes na pele, agravando o quadro de mastite $[2,4,14]$. A escolha do antimicrobiano para o tratamento deve ser feita, preferencialmente, com base no TSA. O princípio ativo utilizado deve ser testado periodicamente para evitar a troca desnecessária do antimicrobiano e para prevenir a disseminação de agentes resistentes, ao utilizar um principio ativo ineficaz. [10].

$\mathrm{O}$ maior risco de mastite associado a animais de alta produção é, provavelmente, conseqüência do fato desses animais pertencerem a uma categoria mais exigida. Há um desvio de maior quantidade de energia de outras funções para a produção leiteira e, dessa forma, o sistema imune pode ser prejudicado, causando um aumento da susceptibilidade a doenças [2]. Esperava-se uma associação linear positiva entre idade e ocorrência de mastite, pois animais jovens apresentam um melhor funcionamento das células polimorfonucleadas [14]. Isto pode explicar o aumento gradativo do risco que foi observado. Entretanto, a redução do risco encontrada após os 75 meses de idade contradiz o resultado esperado. Este dado pode estar associado a um viés de seleção, onde os animais menos resistentes são eliminados antes desta idade. A associação entre mastite contagiosa e tempo de lactação pode ter ocorrido em função de alguns animais terem parido mais cedo, estando em ordenha há mais tempo e, consequientemente, expostos ao risco por um período maior [14].

\section{CONCLUSÃO}

O surto descrito foi provavelmente causado pela introdução de animais infectados no rebanho. Outros fatores, como deficiências técnicas na ordenha, podem ter agravado o surto, possibilitando a disseminação dos agentes. A recomendação técnica para este caso inclui tratamento, secagem e descarte de animais, observadas análises de históricos sanitários, produtivos e reprodutivos.

Práticas de manejo e fatores ambientais têm grande influência no desenvolvimento de mastite e são responsáveis pela variação da freqüência de infecção observada entre os rebanhos [2,13]. Dessa forma, a incidência de mastite clínica e subclínica varia de acordo com o grau de higiene e tecnificação da produção de leite. A implantação de técnicas adequadas de manejo de ordenha, controle de mastites e de nutrição é fundamental para a normalização da CCS do leite do tanque, bem como para evitar novos casos.

Agradecimentos. Ao Dr. Cláudio Cruz por sua colaboração através de informações oriundas de experiência clínica em bovinos leiteiros. 


\section{REFERÊNCIAS}

1 Auldist M.J. \& Hubble I.B. 1998. Efects of mastitis on raw milk and dairy products. The Australian Journal of Dairy Technology. 53: 28-36.

2 Bramley A.J., Cullor J.S., Erskine R.J., Fox L.K., Harmon R.J., Hogan J.S., Nickerson S.C., Oliver S.P., Smith K.L. Sordillo L.M. 1998. Current Concepts of Bovine Mastitis. Madison: National Mastitis Council, 64 p.

3 Brasil, Ministério da Agricultura, Pecuária e Abastecimento. Instrução Normativa n. 51, de 18 de setembro de 2002.

4 Bray D.R. \& Shearer J.K. 1994. Milking Machine and Mastitis Handbook. Gainesville: Univesity of Florida, 44 p.

5 De Haas Y., Barkema H.W. \& Veerkamp R.F. 2002. The effect of pathogen-specific mastitis on the lactation curve for sometic cell count. Journal of Dairy Science. 85: 1314-1323.

6 De Oliveira C.A.F. 1999. Aspectos relacionados à produção que influenciam a qualidade do leite. Higiene Alimentar. 13: 10-16.

7 Dohoo I.R. \& Meek A.H. 1992. Somatic Cell Counts in Bovine Milk. The Canadian Veterinary Journal. 23: 119-125.

8 Eberhardt R.J., Hutchinson L.J. \& Spencer S.B. 1982. Relationship of bulk tank somatic cell counts to prevalence of intramammary infection and to indices of herd production. Journal of Food Protection. 45: 1125.

9 Erskine R.J. 1992. Mastitis Control in Dairy Herds with High Prevalence of Subclinical Mastitis. The Compendium Collection. 14: 7-15.

10 Guérin-Faublée V., Tardy F., Bouveron C \& Carret G. 2002. Antimicrobial resistance of Streptococcus species isolated from clinical mastitis in dairy cows. International Journal of Antimicrobial Agents. 19: 219-226.

11 Guterbock, W. M. 1994. Practical Aspects of Mastitis Control in Large Dairy Herds, Part III: Milking Equipment. Mastitis Control in Large Dairy Herds. 6: 28-33.

12 Harmon R.J. 1994. Physiology of Mastitis and Factors Affecting Somatic Cell Counts. Journal of Dairy Science. 77: 21032112.

13 Philpot W. N. \& Nickerson S.C. 1991. Mastitis: Counter Attack. A strategy to combat mastitis. Naperville: Babson Bros. Co., $150 \mathrm{p}$.

14 Radostits O. M., Leslie K. E. \& Feltrow J. 1994. Mastitis Control in Dairy Herds. In: Radostits O.M., Leslie K.E. \& Feltrow J. (Eds). Herd Health - Food Animal Production Medicine. Philadelphia: Saunders, pp.229-276.

15 Thursfield M. V. 2004. Descrevendo a Ocorrência de Doenças. In: Thursfield M.V. (Ed). Epidemiologia Veterinária. São Paulo: Rocca, pp.47-73. 